\title{
Pharmaceutical Applications of Polymeric Nanomaterials
}

\author{
Libo $\mathrm{Wu}^{1}$ and Lu Sun ${ }^{2}$ \\ ${ }^{1}$ Pharmaceutical Development Department, MAP Pharmaceuticals, Inc., Mountain View, CA 94043, USA \\ ${ }^{2}$ Department of Engineering and Technology, Indiana University-Purdue University Indianapolis, Indianapolis, IN 46202, USA
}

Correspondence should be addressed to Libo Wu, lwu@mappharma.com

Received 5 December 2010; Accepted 5 December 2010

Copyright $\odot 2011$ L. Wu and L. Sun. This is an open access article distributed under the Creative Commons Attribution License, which permits unrestricted use, distribution, and reproduction in any medium, provided the original work is properly cited.

With significant attention focused on nanoscience and nanotechnology in recent years, nanomaterials have been used in a wide variety of applications such as automotive, environmental, energy, catalysis, biomedical, drug delivery, and polymeric industries. Among those fields, the application of nanomaterials with pharmaceutical science is an emerging and rapidly growing field and has drawn increasing attention recently. Research and development in this field is mainly focused on several aspects such as the discoveries of novel functional nanomaterials, exploration on nanoparticles with controlled and targeted drug delivery characteristics, and investigation of biofunctionalized and diagnostic nanomaterials. In this special issue, we have invited a few papers related to recent advances in pharmaceutical application of polymeric nanomaterials.

The first article of this special issue provides a comprehensive literature review on the application of polymeric nanoparticles in cancer drug delivery especially on temperature and $\mathrm{pH}$-responsive drug delivery systems. The second paper examines properties of the PLGA-chitosan nanoparticle/plasmid DNA complex after formation, determines the optimal ratio of plasmid DNA: nanoparticles for nucleic acid delivery purposes, and elucidates the location of the pDNA within the complexes. The third paper demonstrates an alternative way to monitor the viability of cells adhered on a nanoporous polymer film prepared by laser interference pattering in real time. The fourth paper uses mechanically embossed polyester films to analyze the dynamics of cell alignment and cell-specific factors modulating the response of chinese hamster ovary cells and of a rat myogenic cell line to the surface topography. The fifth article develops methotrexate-human serum albumin conjugates by a simple carbodiimide reaction and evaluates its cytotoxicity. The sixth paper proposes to produce a self-microemulsifying docetaxel using PLGA, tetraglycol, labrasol, and cremophor ELP. The prepared Dtx-loaded self-microemulsifying system shows an inhibitory effect for proliferation of B16F10 melanoma cells. The seventh paper describes a straightforward production methodology of paramagnetic microparticles with homogeneous and selectable sizes using flow focusing technology and reports the development of an initial formulation of a stable iron oxide suspension compatible with the flow focusing requirements. The eighth paper proposes the use of nanostructured materials $\left(\mathrm{TiO}_{2}\right.$ and $\left.\mathrm{Fe}_{2} \mathrm{O}_{3}\right)$ for simultaneously coloring and/or improving the antimicrobial properties of PMMA resins. The ninth paper clarifies the effects of water-soluble chitosan and water-soluble chitosan nanoparticles on hypercholesterolemia induced by feeding a high-fat diet in male Sprague-Dawley rats. The tenth article presents the microspheres based on the protein Zein (ZN) and $\mathrm{ZN}$ associated to the natural polymer chitosan. The last paper of this special issue describes a novel methodology comprised of microdialysis and optical imaging to assess the liposome stability in vivo.

Libo Wu Lu Sun 

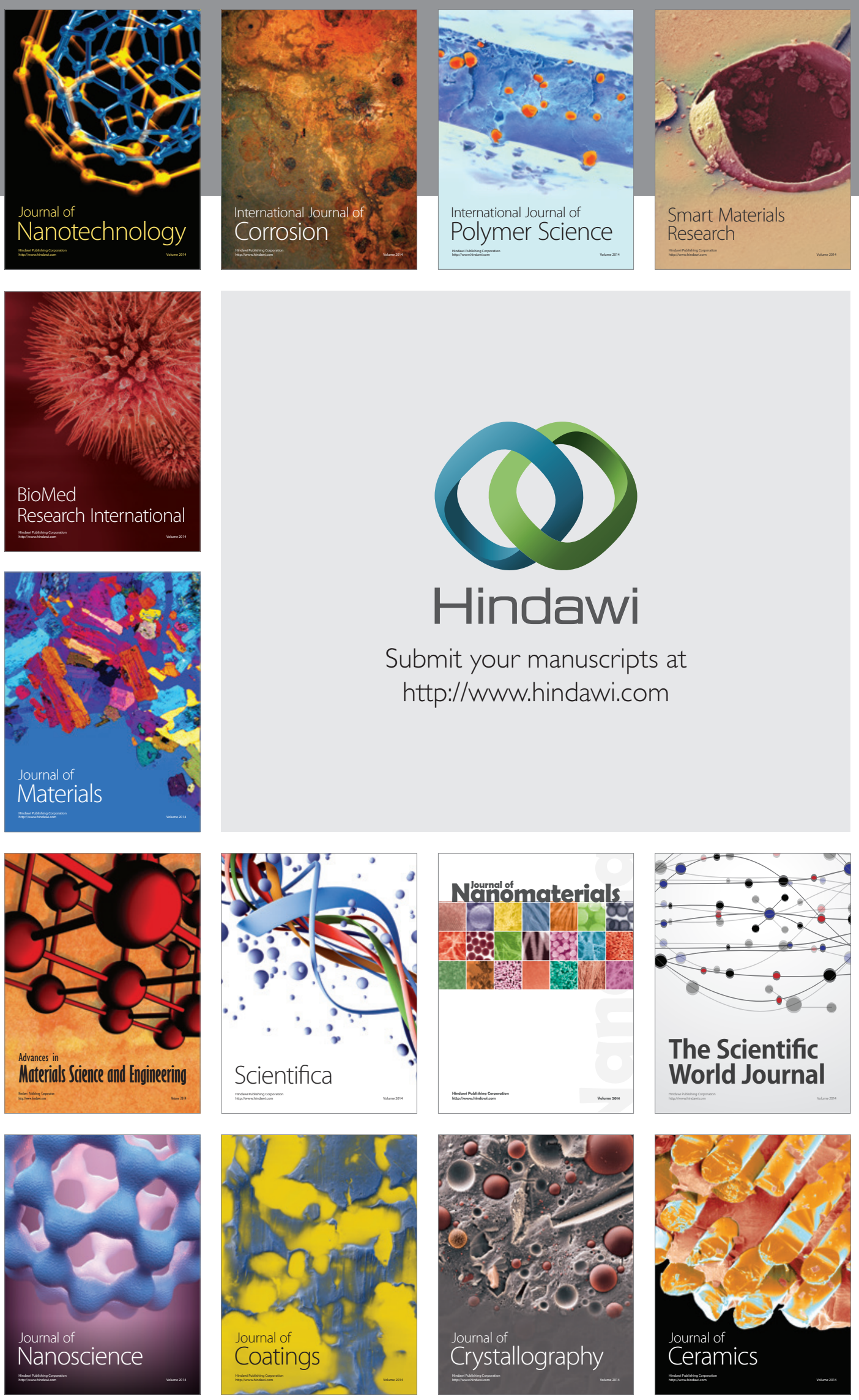

The Scientific World Journal

Submit your manuscripts at

http://www.hindawi.com

\section{World Journal}

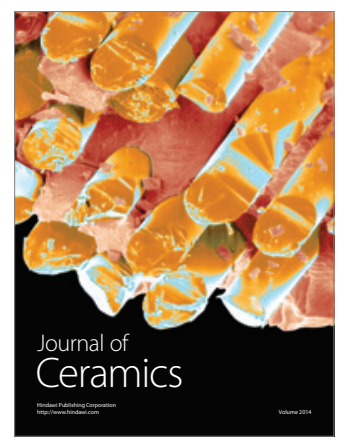

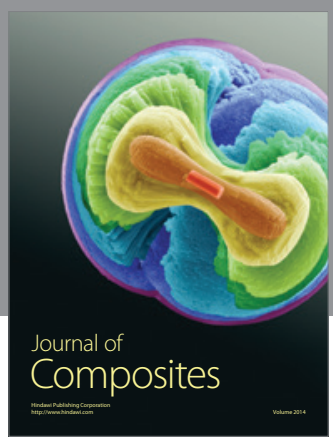
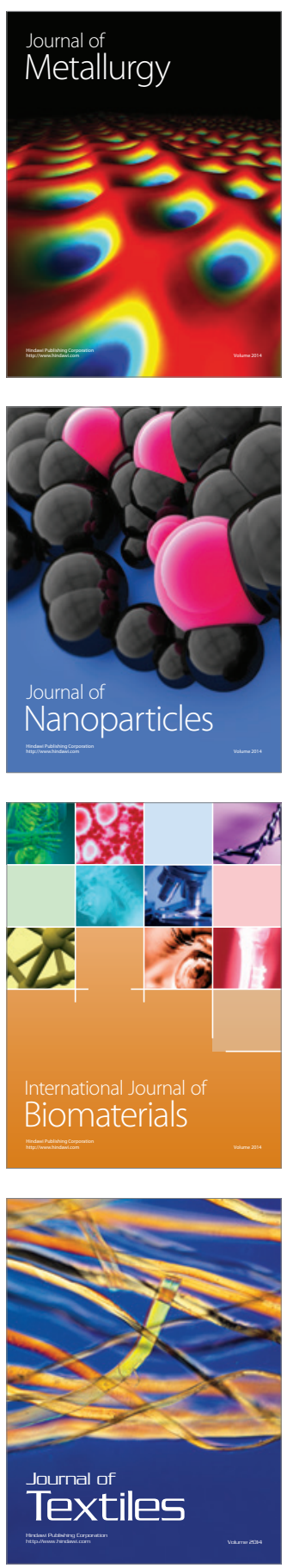